\title{
A Brave Old World: An Analysis of Scientific Racism and BiDil ${ }^{\circledR}$
}

\author{
Joel Z. Garrod*
}

QUESTION: What is the difference between black natives slicing up a white missionary, and a white mob lynching a helpless Negro? Answer: very little - and, for the victims, none at all. Whatever the reasons, whatever the excuses, whatever the motives, the basic behaviour mechanism is the same. They are both cases of members of the in-group attacking members of the out-group. - Desmond Morris (1)

In Racialized Boundaries: Race, Nation, Gender, Colour and Class and the Anti-Racist Struggle, Floya Anthias and Nira Yuval-Davis state:

Race is one way by which the boundary is to be constructed between those who can and those who cannot belong to a particular construction of a collectivity or population. In the case of race this is on the basis of an immutable biological or physiognomic difference which may or may not be seen to be expressed mainly in culture or life-style but is always grounded on the separation of human populations by some notion of stock or collective heredity of traits (2)

While Anthias and Yuval-Davis' statement reflects the most common association between race and genetically inheritable traits, the science involving this subject is often imprecise, and more often, simply false (3). The phrase, "some notion of stock or collective heredity of traits" (2), implies an uncertainty towards what has consistently throughout history been understood as a proven biological truth, regardless of evidence stating the opposite (4). In fact,

[t]he Western concept of race, although socially

\footnotetext{
* To whom correspondence should be addressed: Zackary Garrod, 2061 Ocean Forest Drive, Surrey, B.C. Canada. V4A 6P1

Phone Number: (604) 617-4664

Email Address: jzgarrod@gmail.com
}

constructed, was always rooted in 'biological' features; that is, the characteristics used to classify individuals into races were always assumed to have a basis nontrivially

rooted in human biology (5).

Many scientists have been satisfied to use false statistics, poor methodology, and illogical conclusions to "prove" the theory that biology is a predictor of culture, without regard for real evidence stating the opposite (6).

Without any concrete evidence, why would scientists want to go to all the trouble to create distinct biological races? According to Maria Castagna and George J. Sefa Dei, "whites created different 'sciences' and 'scientific' theories to justify, legitimize and maintain the existing social order" (6). Therefore, rather than being based solely in objective observation, scientific racism is a scientific tradition in which biology is used not only to prove the existence of race, but also, to maintain existing social hierarchies.

The recent Food and Drug Administration (FDA) approval of BiDil ${ }^{\circ}$, a congestive heart failure drug created by NitroMed ${ }^{\circledR}$, looks to continue and reinforce this tradition of scientific racism. Marketed specifically to African Americans, it is the first drug to specifically target a racial group (7). A combination of $20 \mathrm{mg}$ of isosorbide dinitrate and $37.5 \mathrm{mg}$ of hydralazine hydrochloride (8), the two components have "been used for years to treat high blood pressure and agina (chest pain)" (9). While isosorbide dinitrate "helps the body make a tiny molecule called nitric oxide [. . .] hydralazine helps prevent its rapid destruction" (9). This creation of nitric oxide allows the arteries to widen and lets blood travel through them more easily, "decreasing the heart's workload" (9). While researchers believe that $\mathrm{BiDil}{ }^{\circledR}$ works best in 
individuals that produce low levels of nitric oxide, "a few small studies suggest that blacks have more difficulty making or using nitric oxide than whites. Not all blacks have this trouble of course, nor does everyone else have plenty of nitric oxide" (9).

BiDil@'s approval raises important questions about the future of genetic-based medicine, as "some experts worry about the precedent of accepting race as a crude marker for underlying biological differences - which could still leave many individuals being treated with drugs that don't work well for them" (7). By using race to distinguish who is more suited to use a drug, pharmaceutical companies are practicing a modern form of scientific racism, and ignoring the social reasons as to why African Americans are twice as likely to develop congestive heart failure (10).

To understand modern scientific racism, however, it is important to understand what scientific racism is, and how it has been used in the past. While science has the reputation of objectively testing theories using the scientific method, scientific racism is the exact opposite. It seeks to create definitions of race and culture based on opinion and extremely questionable evidence: "Supposed scientific evidence was marshalled, to establish both the existence of different racial types, and their depiction within a hierarchy of superior and inferior, where the Black was regarded as inferior" (2). The important distinction between science and scientific racism is that the creation of separate racial categories was not solely for the sake of a biological system of classification, but rather for political means:

Preconceived notions of European superiority led to a

nonscientific justification for European social dominance

[. . .] Such justification could then have been transformed

into a biological theory based on biased science intended

to validate European preconceptions (5).

These preconceptions were based on the idea that nature, and not social forces, created divisions in society, and consequently "the physiological, cultural, and economic woes of the poor and the nonaffluent 'middling classes' were scientifically ordained by Nature, and therefore neither preventable nor reversible" (3). This concept of hereditary social traits is extremely important to scientific racism as it explains social inequalities not in terms of the society failing to provide for its citizens, but rather a group's failure to have superior breeding.

One of the first racial theories to be developed was that of polygenism, "which held that the human races had been created separately" (5), authored by Swiss physician Paracelsus in 1520. This theory held that God had created the white race as superior, and therefore separate to other races, creating a hierarchy of races as measured by God (5). While polygenism was not "science", the attitude it created towards other ethnic groups allowed scientific racism to flourish in light of the slave trade, which was seen to reinforce polygenistic beliefs:

The slave trade not only brought together populations that previously had been geographically separated but also brought them together under conditions of manifest social inequality. That is, phenotypic characteristics were used to symbolize social status (5).

European success in dominating other civilizations was seen as evidence from God of their superior genetic heritage.

The modern biological system of classification, however, "began with Carolus Linnaeus (1707-1778), who developed the binomial nomenclature system to classify and organize plants and animals" (5). Linnaeus' classification system was extremely important in determining a system of classification based on specific - normally phenotypic - traits. His description of Homo Sapiens includes four distinct varieties: "H. sapiens europaeus, $H$. sapiens afer, $H$. sapiens asiaticus, and $H$. sapiens americanus" (5), ranging from $H$. sapiens europaeus on the one end, to $H$. sapiens afer at the other, keeping "consistent with the general views and approach of other eighteenth-century naturalists examining race" (5). While Linnaeus' classification system and taxonomy in general "is directly related to one's central theory of how and why to classify organisms into groups" (5), it is important to recognize the social placement of those doing the classifications. While most naturalists argued as to the relative placement of other races, "they concurred that Europeans occupied the highest position on the scale of nature" (5).

Although Thomas Jefferson spoke of all men as being "created equal", observations of his own slaves led him to believe that "Negro inferiority was obvious, [and] the criteria by which it might be established would have to be determined by science" (5). One of the most influential pre-Darwinian racial theorists, Jefferson's call for science to determine the obvious "inferiority" of African Americans is an extremely important stage in the evolution of scientific racism. While earlier naturalists concluded that there was a "hierarchy of human races, they saw all races as members of the human species" (5).

The beginning of the nineteenth century, however, saw a revival of polygenist thinking and a shift in the racial paradigm. While there was no question regarding the inferiority of the "Negro race", there was "debate concerning whether Negroes represented a distinct species from the other human races" (5). Polygenists such as Louis Agassiz, Samuel Morton, Josiah Nott and 
George Robin Gliddon used various methods, including the measurement of cranial volume, to determine genetic inferiority of the African race (5). Their evidence failed to suggest any form of genetic difference based on race, yet they continued to proliferate scientific racism throughout their lives (5).

While these earlier theories failed to provide any form of concrete proof surrounding many biological issues, Charles Darwin's theory of evolution and natural selection provided logical evidence that addressed "the origin and maintenance of biological diversity" (5). Darwin's theory succeeded where others did not due to "directly observable biological phenomena, such as the resistance to pesticides and antibiotics, our ability to produce new food crops, and the postponement of the aging of laboratory animals" (5). His theory has had such an impact on genetics and race that "[a]fter Darwin, any ranking of human beings by specific criteria would need scientific (that is, testable) justification" (5).

Furthering Darwin's concept of natural selection, sociologist Herbert Spencer "coined the term 'survival of the fittest'" (5) in response to growing social inequality in both England and the United States. Adapting Darwin's evolutionary theories to the social landscape, Spencer would conclude that millionaires "were the product of natural selection, the bloom of the competitive society" (5). Essentially, Spencer's social darwinism mirrored polygenism without the religious connotations; successful groups of people, whether based on race or other factors were a product of biologically superior genetic inheritance. This thinking would lead others such as Sir Francis Galton to develop the areas of eugenics, pseudoscience, and psychometry ${ }^{1}$. These new "sciences" would retain the same irresponsible practices and methodologies as their former iterations.

Yet, while scientific racism appears to be a result of past irresponsible scientific practice, it has hardly fallen out of popular favour. In his 1997 book, 'Why Race Matters', Michael Levin is quoted as saying: "If breeds of dog may differ in intelligence and temperament, there seems to be no reason evolution could not have differentiated human groups along similar lines" (11). Responding to current sociological claims that race is socially constructed (5), Levin states: "As the accumulating evidence has made group differences harder to deny, one is apt to be told they do not matter" (11). Continuing the tradition of scientific racism, Levin does not provide any substantial evidence to support his claims, instead choosing to discuss the genetic inheritance of particular species of animals, heritability

1 The belief that intelligence is an inherited trait (5) of personality, and IQ testing between both blacks and whites (11). Vincent Sarich and Frank Miele similarly discuss race in their 2004 book, 'Race: The reality of human differences', discussing social and scientific factors that "prove" the existence of different races. Like Levin, Miele and Sarich provide faulty and illogical evidence to support their claims:

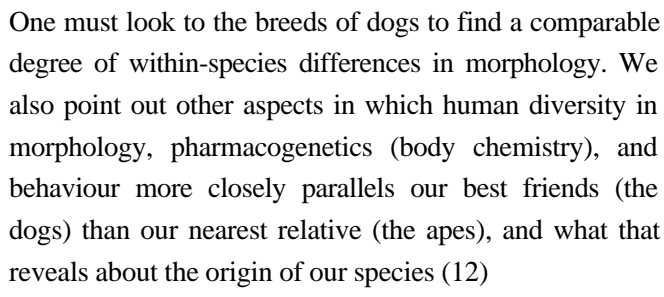

What Levin, Sarich and Miele fail to recognize is that "individual genetic traits are inherited independently" (5), not as a group. Therefore culture, intelligence, athletic ability, et cetera cannot be racially linked due to the independent nature of these genetic traits.

A further illustration of this would be the commonly misused example of sickle disease and malaria "to support the biological foundation of race" (13). While sickle disease is "caused by a specific mutation in the haemoglobin gene [. . .] [it] appeared in, at least, four independent regions of the world, including Central and North Africa, Spain, Arabia, and India" (13). Bernard Swynghedauw states:

In homozygous persons, the mutation is fatal and patients died from severe anaemia and its consequences. In contrast, in heterozygous persons, the mutation provides a selective advantage because patients are resistant to malaria [. . .], and the contemporary map of sickle disease can be superimposed on that of malaria. In fact, such an evolutionary advantage was crucial for the geographic distribution of the disease in three continents [. . . ] between black and white Africans, Spanish, Arabs and Indians (13).

Swynghedauw continues to make clear the issue that "race has nothing to do with such a distribution, and, in no sense, can sickle disease support the assumption that race or even ethnicity has a biological basis" (13). While interbreeding populations will most likely share genetic traits - such as resistance to or susceptibility to particular diseases - these traits cannot be assumed by phenotypic differences or racial classifications as is done in the work of Levin, Sarich and Miele suggests.

Similarly, difficulties arise in not only finding societies composed solely of phenotypically homogeneous individuals, but also in finding individuals that identify themselves as made up of distinct races. Swynghedauw describes the "human race" as "an extremely vague concept, with several, and contradictory definitions, mixing geographical (Asians), religious (Jews), and imaginary (Caucasians) origins, together with biologic phenotypes (Black)" 
(13). He also raises an interesting point:

Race is a parameter that cannot be measured accurately and cannot even be defined using objective criteria. Why skin colour? Why not height, which confers a strong evolutionary advantage? Or baldness - which is neutral? How do we classify mulattos? If one drop of black blood is enough to become black, why not the reverse? (13).

Barring the difficulties in trying to measure and classify race, "data from the last US census showed that even self-identification of race was problematic, since 7 million people identified themselves as members of more than one race, and about 800,000 respondents said they were both black and white" (13). In our cosmopolitan world it is becoming more and more difficult to identify the "racial" identity of an individual and according to John E. Clark, president of the Association of Black Health-System Pharmacists (ABHP), racial identification in terms of skin colour is not enough: "For me to call someone 'black' because they [have] black skin may be inappropriate because they may not see themselves as that" (8). If there was ever such a thing as genetically-distinct "races", they have long-since disappeared due to a world that has become a global village, blending different ethnicities and ambiguous racial definitions with multiple socioeconomic and geographic factors which have the ability to affect the genetic inheritance of every group and individual (13).

Going beyond simple phenotypic differences, however, the results of the Human Genome Project provide further evidence against the racial concept: "The genotypes of 'White', 'Black', 'Asians' are remarkably identical, and there are no more than $0.1 \%$ variations in 35000 genes that have been identified so far in the human genome" (13). A further study focusing on the "classical seven 'races'" (13) in different geographical locations found that "the withinpopulation diversity is much wider than the betweenpopulation or between-races diversity [. . .] From a genetic point of view, it is more difficult to distinguish one person from another, than a black from a 'Caucasian'" (13). As well, Swynghedauw relates the results of another study in which individuals were assigned to different "subclusters on the basis of their genotype, ignoring their actual population or racial affiliations" (13). This study found similar results, such that "62\% of Ethiopians belong to the same cluster as Norwegians, together with $21 \%$ of the Afro-Caribbeans, and the ethnic label 'Asian' inaccurately describes Chinese and Papuans who were placed almost entirely in separate clusters" (13). The heterogeneous nature of our society, along with genetic evidence of commonality between the human "races" distinguishes modern studies such as these from those by Levin,
Sarich, Miele and others, which demonstrate a similarity to past scientific racism in their use as an oppressive tool. While it was historically "believed that biology held the key to solving social problems" (4), it has instead often been used as justification for slavery, oppression, and manifest social inequality.

While scientific racism has predominantly targeted black populations, Alan Chase argues:

Now, as in 1798, scientific racism remains color-blind and

free of all racial, religious, and cultural biases. It is not concerned with people but, simply, with what is known as the maximization of profits and the minimization of taxes on these profits - particularly when these taxes are earmarked for promoting the health, education, and general welfare of the men and women whose labors make such profits possible in the first place (3).

Chase's statement seems to reflect eerily on the FDA's recent aproval of BiDil@. While the intentions of NitroMed ${ }^{\circledR}$ are certainly contentious (16), the use of science in the marketing of the drug provides African Americans with rudimentary explanations of why the drug works better for their particular population: "Critics point out that while the trials showed that BiDil® saved lives, they failed to show whether the drug worked better in blacks than in other groups or that it worked only in blacks" (14).

While the past practice of using inadequate science to demonstrate racial difference is the supreme tenet of scientific racism, the FDA's approval of BiDil ${ }^{\circledR}$ could set a dangerous precedent. In a "society obsessed with the sanctity of 'Science'" (15), scientific evidence is taken extremely seriously. Yet, this has serious consequences for the marketing of a race-specific drug, such as BiDil®. In a letter to the editor of Nature, Jonathan Kahn points out how "simplifying" research in various media transforms the meaning to imply fact (emphasis in bold added):

\section{Los Angeles Times}

"[A] report in the journal Nature Genetics last month [that] listed 29 drugs that are known to have different efficacies in the two races."

\section{New York Times}

"By one count, some 29 medicines show evidence of being safer or more effective in one racial group or another, suggesting that more targeted medicines may be coming."

\section{John Entine}

"Only last month, the prestigious journal Nature Genetics reported that at least 29 medicines have so far been identified that are either safer or more effective in certain populations because of genetic differences between those population groups" (16) 
The basis for the rhetoric used to market BiDil ${ }^{\circledR}$ specifically to African Americans is somewhat unclear as the drug has not been tested on various ethnic groups (9). While African Americans may happen to "respond better on average to BiDil than whites, [. . .] the drug will still be ineffective for those who don't possess a particular cardiac physiology or combination of genes" (7). The use of scientific evidence to market BiDil®, regardless of whether the evidence is an accurate descriptor of whom the drug is targeted to, remains fixed in the tradition of scientific racism. In one Newsweek column about the drug, there is a caption that reads: "Positive discrimination: BiDil, a drug to prevent heart failure, will be targeted at black patients" (10). The caption is placed conveniently underneath a picture of a black patient being tended to by a black doctor.

NitroMed@'s marketing scheme remains questionable with further analysis of the media rhetoric. The corporate sponsor of the A-HeFT trials (African American Heart Failure Trial), NitroMed ${ }^{\circledR}$ has consistently linked BiDil ${ }^{\circledR}$ to the "29 medicines" included in the trial, "paired to give the impression that there is some 'real' difference underlying racial response to these drugs" (16). Yet, of all these 29 medicines, "only 4 [...] provide evidence of a genetic cause for the differential drug response and only an additional 9 provide evidence that 'the association has a reasonable underlying physiological basis'" (16). Similarly, for the other sixteen medicines there has been,

no demonstration of a physiological basis to any observed difference [. . .] moreover, of the 13 medicines with some supporting evidence of racial difference, three were ACE inhibitors, whose claims of racial difference have been hotly contested in the professional literature, and one was BiDil (16).

Understanding these issues surrounding BiDil@'s approval are extremely important for responding to it in a critical manner. It is significant to note that the FDA "had rejected the same two-drug pill in 1997, after a multiracial trial found it less effective than a common class of drugs [. . .] But in parsing the trial data, researchers noticed results were strong among African Americans" (10). The strength of the results in African American patients led to a new trial in "1050 black patients. BiDil reduced deaths by $43 \%$, proving so successful that the trial was stopped early" (7). While the marketing of BiDil ${ }^{\circledR}$ seeks to emphasize the positive nature of stopping congestive heart failure in African American populations, it also seeks to deemphasize the evidence that suggests genetic differences do not discriminate between particular ethnic groups.

Yet, while BiDil ${ }^{\circledR}$ continues to be marketed as a positive race-specific drug, Troy Duster, president of the American Sociological Association describes the process as "inadequate science [. . .] It's a dangerous shortcut" (10). Similarly, Gary Puckrein, executive director of the National Minority Health Month Foundation states: "This really isn't a race drug, but a drug that works in specific populations for reasons we don't yet understand" (14). Regardless of evidence and claims that suggest otherwise, NitroMed®'s goal of marketing BiDil® to African Americans assumes a biological difference - even if they don't believe it. Their own Dr. Jay Cohn, the University of Minnesota researcher who developed $\mathrm{BiDil}{ }^{\circledR}$ "concedes race is a crude standard for treatment decisions. 'Unfortunately' he says, 'we don't have a more precise guide at the moment'" (10). While the admission of race as a "crude standard for treatment" (10), suggests a difference between past scientific racism and BiDil ${ }^{\circ}$, the marketing of the drug is consistent with past scientific tradition. Similar to Linnaeus' classification system, NitroMed®'s decision to market BiDil@ "exclusively to members of one race" (10), suggests that biological differences separate races, indicating who can or cannot use particular functions of society.

It seems relevant now to refer back to Alan Chase's comment that scientific racism is based not on people, but the maximization of profits (3), especially when investigating NitroMed $\AA$ 's motives behind getting approval for a race-specific drug. Kahn suggests that,

[p]erhaps the answer lies not in medicine, but in commerce. NitroMed holds a patent for a non-race specific use of BiDil, which expires in 2007; it also holds a racespecific patent that lasts until 2020. This extra 13 years of patent protection may present a compelling commercial reason for seeking to cast BiDil as a racial drug, even though to do so is not supported by the medical evidence (16).

Understanding that BiDil@'s marketing campaign is not fully supported by medical evidence is important in demonstrating similarities with past scientific racism. While pseudoscience, craniology, psychometry, and polygenism failed to be supported by factual evidence, their effects and consequences on society remain extremely large.

Similarly, "attempts to address genetic difference may be located at the level of the molecule and targeted by pharmaceuticals developed and dispensed through the purportedly impersonal forces of the market" (16). This in turn creates a dangerous precedent "that the pharmaceutical industry will move towards single-race drug studies for its own convenience" (10). Unfortunately, it seems this practice has already taken place with NitroMed®'s introduction of $\mathrm{BiDi} 囚 1$, as Dr. Jay Cohn's admissions that "we don't have a more 
precise guide at the moment" (10) indicate that NitroMed® felt race was the easiest and most convenient marker of genetic traits at this time. If the maximization of profits is the sole goal of these pharmaceuticals there seems to be little "incentive to go beyond using race or other crude surrogates, when to do so would entail costly research and might narrow their target markets" (7). The decision to market BiDil® as a race-specific drug suggests biological differences without proper testing of those differences.

More importantly, however, the approval of BiDil® raises serious questions as to the social consequences of race-specific drugs. BiDil® appears as a "quick fix" for what NitroMed®'s marketing suggests is a racial problem rooted in a myriad of factors, including biological differences. If past scientific racism used fixed notions of European dominance to create a nonscientific rationale for European social authority, "such justification could then have been transformed into a biological theory based on biased science intended to validate European preconceptions" (5). With this understanding of scientific racism, it seems clear to link BiDil@ to this tradition. Much like scientific racism's position as a political entity, Kahn states:

At work here is an appropriation of race as reified in the BiDil story to serve larger political agendas aimed at transmuting health disparities, rooted in social and economic inequality, into mere health differences, rooted in biology and genetics (16).

In this sense, BiDil@ perfectly reflects the tradition of scientific racism by using biological differences in relation to growing social problems.

One issue that fails to be mentioned in the media rhetoric and marketing slogans, however, is poverty among African American populations. As Anthony Polednak states:

Today, access to and quality of medical care may still differ for blacks and whites within each level of social class due to the effects of discrimination and racism [. . .] populations at highest risk for medical problems (such as poor urban black) may have 'limited contact with the health care system except for emergencies' (17).

If African Americans are twice as common to develop congestive heart failure and die more often as a result (10), this may well be directly related to "limited contact with the health care system except for emergencies" (17). As well, Polednak's studies indicate that,

[1]ack of a primary-care physician and health insurance, as well as a related pattern of receiving care at hospital emergency rooms rather than physicians' offices, were associated with noncompliance with treatment and the occurrence of hypertension emergencies in this case- control epidemiologic study (17)

Suggesting that African Americans' treatment choice is a result of "noncompliance of treatment" (17) and not social inequalities, reinforces scientific and medical racism. Solely because an African American does not have health insurance and more often receives care in emergency situations does not suggest causality towards noncompliance, but rather a lack of economic capital to afford those decisions. What is ignored by NitroMed ${ }^{\circledR}$ and other race-specific drugs is the common thread between all of Polednak's studies in which there "appears to be poorer primary care for blacks" (17), and the lack of questioning as to why this is taking place.

What NitroMed® also fails to engage is the effect of discrimination and racism in relation to blood pressure - a leading cause of congestive heart failure (17). Although a study in Alameda County, California involving 51 black and 50 white women 20-80 years old did not reach statistically significant levels, it is important to recognize that "racial discrimination was positively associated with the prevalence of selfreported high blood pressure among blacks" (17). Similarly, "the viewing of scenes depicting racist situations was associated with acute increases in measured blood pressure or heart rate in samples of black college students" (17). While these studies may not have evidence that heart disease is a direct result of racism and discrimination, their results suggest at least some connection between the two for African Americans.

BiDil@'s approval represents both an intentional and unintentional form of racism inherent through its creation and its marketing. While NitroMed ${ }^{\circledR}$ is intentionally distributing the drug to members of one race, it is also unintentionally reinforcing the unproven belief that races are separated by distinct biological differences. The FDA's decision to approve BiDil® "for sale with a label designating African Americans as the target population" (7), reinforces scientific racism, while at the same time, ignoring the social consequences of a "quick fix" race-specific drug. There seems to be little difference between NitroMed®'s decision to create BiDil ${ }^{\circ}$ and past scientific claims towards white racial superiority. If the purpose of scientific racism is to, "blame the hereditary endowments 'in the blood' of the ill, the uneducated, and the poor for their chronic (and eminently environmental) infections and hunger diseases, for their illiteracy and above all else for their poverty" (3), then NitroMed® is guilty of symbolically blaming African Americans for having high levels of congestive heart failure by failing to recognize and deal with the social inequalities that lead to such health problems. Similarly, 
the FDA's approval of BiDil@ sends a message to other pharmaceutical companies "that race and genetics correlate closely enough to provide the basis not only for general medical practice but also for addressing specific health disparities" (16). This sets a dangerous precedent that race can substitute for genetic differences due to the lack of "a more precise guide" (10). Pharmaceuticals must "move without delay from blurry surrogates for drug response to more specific causes" (7) in order to halt the production of yet another form of scientific racism and instead, focus on developing the science that will, once and for all, prove Jefferson's claim that all men are created equal (5).

\section{REFERENCES}

1. Morris D. The Human Zoo. Toronto: Clarke, Irwin \& Co Ltd; 1969.

2. Anthias F, Yuval-Davis N. The Concept of 'Race' and the Racialization of Social Divsions. In: Racialized Boundaries. London: Routledge; 1992: 1-20.

3. Chase A. The Legacy of Malthus. New York: Alfred A Knopf; 1997.

4. Barkan E. The Retreat of Scientific Racism. New York: Cambridge University Press; 1992.

5. Graves JL. The Emperor's New Clothes: Biological Theories of Race at the Millennium. New Brunswick: Rutgers University
Press; 2001.

6. Castagna M, Sefa Dei GJ. An Historical Overview of the Application of the Race Concept in Social Practice. In: Calliste A, Sefa Dei GJ, eds. Anti-Racist Feminism: Critical Race and Gender Studies. Halifax, Nova Scotia: Fernwood; 2000: 19-37.

7. Wadman M. Drug Targeting: is race enough? Nature 2005; 435: 1008-1009.

8. Thompson CA. New heart-failure therapy takes race into account. American Journal of Health-System Pharmacy 2005; 62(17): 1745-1748.

9. Gray area for new heart failure drug. Harvard Heart Letter 2005 16(3): $1-2$

10. Barrett J. A Race-Based Heart Remedy. Newsweek 2005 145(26): 24.

11. Levin M. Why Race Matters: Race Differences and What They Mean. Westport, Connecticut: Praeger; 1997.

12. Sarich V, Miele F. Race: The reality of human differences. Boulder, Colorado: Westview Press; 2004.

13. Swynghedauw B. Human races and evolutionary medicine. European Review 2003 11(3): 437-447.

14. Coates TP. Suspicious Minds. Time 2005 166(1): 36.

15. Guillaumin C. The Changing Face of 'Race'. In: Bulmer M, Solomos J, eds. Racism. Oxford, UK: Oxford University Press; 1999: 355-362.

16. Kahn J. Misreading race and genomics after BiDil. Nature Genetics2005; 37(7): 655-656.

17. Polednak AP. Segregation, Poverty, and Mortality in Urban African Americans. New York: Oxford University Press; 1997.

Joel Zackary Garrod has recently obtained a Double Major Bachelor's Degree of Arts from University of British Colombia in both English and Sociology. He is currently traveling in Europe, and hopes to obtain an MBA in the future in order to investigate new models of healthcare delivery in Canada. 